\title{
SEJARAH ROUTING PROTOKOL
}

\author{
Muhammad Arif \\ 175100040, KDV \\ Fakultas Komputer \\ Muhammadarif.student@umitra.ac.id
}

\begin{abstract}
Perkembangan IT saat ini menuju dengan konsep-kosenp social networkingnya. Saat ini terdapat trend teknologi yang masih terus digali dalam penelitianpenelitian para pakar IT di dunia, yaitu Cloud Computing Apabila jaringan memiliki lebih dari satu kemungkinan rute untuk tujuan yang sama maka perlu digunakan dynamic routing. Sebuah dynamic routing dibangun berdasarkan informasi yang dikumpulkan oleh protokol routing.Protokol routng didesain tidak hanya untuk mengubah ke rute backup bila rute utama tidak berhasil, namun juga didesain untuk menentukan rute mana yang terbaik untuk mencapai tujuan tersebut. Router saling bertukar informasi routing agar dapat mengetahui alamat tujuan dan menerima tabel routing. Pemeliharaan jalur dilakukan oleh Routing Dinamik.
\end{abstract}

Kata Kunci : Sejarah Routing Protokol 
A. PENDAhuluAN

B. Perkembangan IT saat ini menuju dengan konsepkosenp social networkingnya. Saat ini terdapat trend teknologi yang masih terus digali dalam penelitianpenelitian para pakar IT di dunia, yaitu Cloud Computing Apabila jaringan memiliki lebih dari satu kemungkinan rute untuk tujuan yang sama maka perlu digunakan dynamic routing. Sebuah dynamic routing dibangun berdasarkan informasi yang dikumpulkan oleh protokol routing.Protokol routng didesain tidak hanya untuk mengubah ke rute backup bila rute utama tidak berhasil, namun juga didesain untuk menentukan rute mana yang terbaik untuk mencapai tujuan tersebut. Router saling bertukar informasi routing agar dapat mengetahui alamat tujuan dan menerima tabel routing. Pemeliharaan jalur dilakukan oleh Routing Dinamik.

\section{PEMBAHASAN / STUDI KASUS}

Rumusan masalah yang dapat diambil dari makalah routing dinamis ini adalah :

1. Pengertian routing dinamis ?

2. Contoh Routing dinamis?

3. Kelebihan dan kekurangan contoh Routing dinamis?

4. Perbandingan routing static dan dinamis?

\section{ID SECURITY QWTD4452377-ASP-5244107}

\section{E. KESIMPULAN}

Routing Dinamik adalah jenis routing yang bisa berubah sesuai dengan kondisi yang diinginkan dengan parameter tertentu sesuai dengan protokolnya. Routing Dinamik diterapkan pada PC yang berfungsi sebagai router dan dibutuhkan router lain yang samasama menerapkan sistem routing dinamik, jadi tidak bisa berdiri 
sendiri seperti halnya Router static.

\section{F. Routing Dinamik menentukan gateway untuk network destination berdasarkan parameter yang didapat dari router lainnya melalui Protokol Multicast, seperti metrik, cost dsb. Protocol RIP dan OSPF DISKUSI}

Saya bersama teman saya bernama Rudi mendiskusikan tentang contoh ini dengan sangat baik Hasil diskusi dari materi ini adalah ....( minimal 150 kata )

\section{G. REFERENCE}

[1] O. M. Febriani and A. S. Putra, "Sistem Informasi Monitoring Inventori Barang Pada Balai Riset Standardisasi Industri Bandar Lampung," J. Inform., vol. 13, no. 1, pp. 90-98, 2014.

[2] A. S. Putra, "Paperplain: Execution Fundamental Create Application With Borland Delphi 7.0 University Of Mitra Indonesia," 2018.

[3] A. S. Putra, "2018 Artikel Struktur Data, Audit Dan Jaringan Komputer," 2018.

[4] A. S. Putra, "ALIAS MANAGER USED IN DATABASE DESKTOP STUDI CASE DB DEMOS."

[5] A. S. Putra, "COMPREHENSIVE SET OF PROFESSIONAL FOR DISTRIBUTE COMPUTING."

[6] A. S. Putra, "DATA ORIENTED RECOGNITION IN BORLAND DELPHI 7.0."

[7] A. S. Putra, "EMBARCADERO DELPHI XE 2 IN GPUPOWERED FIREMONKEY APPLICATION."

[8] A. S. Putra, "HAK ATAS KEKAYAAN INTELEKTUAL DALAM DUNIA TEKNOLOGY BERBASIS REVOLUSI INDUSTRI 4.0."

[9] A. S. Putra, "IMPLEMENTASI PERATURAN PERUNDANGAN UU. NO 31 TAHUN 2000 TENTANG DESAIN INDUSTRI BERBASIS INFORMATION TECHNOLOGY."

[10] A. S. Putra, 
"IMPLEMENTATION OF PARADOX DBASE."

A. S. Putra, "IMPLEMENTATION OF

TRADE SECRET CASE STUDY SAMSUNG MOBILE PHONE."

[12] A. S. Putra, "IMPLEMENTATION

PATENT FOR APPLICATION WEB BASED CASE STUDI WWW. PUBLIKLAMPUNG. COM."

[13] A. "IMPLEMENTATION SYSTEM FIRST TO INVENT IN DIGITALLY INDUSTRY."

[14] A. S. Putra, "MANUAL REPORT \& INTEGRATED DEVELOPMENT

ENVIRONMENT BORLAND DELPHI 7.0."

[15] A. S. Putra, "PATENT AS RELEVAN SUPPORT RESEARCH."

[16] A. S. Putra, "PATENT FOR RESEARCH STUDY CASE OF APPLE. Inc."

[17] A. S. Putra, "PATENT PROTECTION FOR APPLICATION INVENT."

[18] A. S. Putra, "QUICK REPORT IN PROPERTY PROGRAMMING."

[19] A. S. Putra, "REVIEW CIRCUIT LAYOUT COMPONENT

REQUIREMENT ON ASUS NOTEBOOK."

[20] A. S. Putra, "REVIEW TRADEMARK PATENT FOR INDUSTRIAL TECHNOLOGY BASED 4.0."

[21] A. S. Putra, "TOOLBAR COMPONENT PALLETTE IN
OBJECT PROGRAMMING."

[22]

A. S. Putra, "WORKING DIRECTORY SET FOR PARADOX 7."

[23] A. S. Putra, "ZQUERY CONNECTION

IMPLEMENTED

PROGRAMMING STUDI CASE PT. BANK BCA Tbk.”

[24] A. S. Putra, D. R. Aryanti, and I. Hartati, "Metode SAW (Simple Additive Weighting) sebagai Sistem Pendukung Keputusan Guru Berprestasi (Studi Kasus: SMK Global Surya)," in Prosiding Seminar Nasional Darmajaya, 2018, vol. 1, no. 1, pp. 85-97.

[25] A. S. Putra and O. M. Febriani, "Knowledge Management Online Application in PDAM Lampung Province," in Prosiding International conference on Information Technology and Business (ICITB), 2018, pp. 181-187.

[26] A. S. Putra, O. M. Febriani, and B. Bachry, "Implementasi Genetic Fuzzy System Untuk Mengidentifikasi Hasil Curian Kendaraan Bermotor Di Polda Lampung," SIMADA (Jurnal Sist. Inf. dan Manaj. Basis Data), vol. 1, no. 1, pp. 21-30, 2018.

[27] A. S. Putra, H. Sukri, and K. Zuhri, "Sistem Monitoring Realtime Jaringan Irigasi Desa (JIDES) Dengan Konsep Jaringan Sensor Nirkabel," IJEIS (Indonesian J. Electron. Instrum. Syst., vol. 8, no. 2, pp. 221-232.

[28] D. P. Sari, O. M. Febriani, and 

A. S. Putra, "Perancangan
Sistem Informasi SDM
Berprestasi pada SD Global
Surya," in Prosiding Seminar
Nasional Darmajaya, 2018, vol.
1, no. 1, pp. 289-294. 